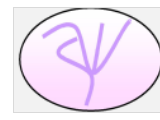

\title{
Prevention of Emotional Disorders and Symptoms Under Health Conditions: A Pilot Study using the Unified Protocol in a Fertility Unit
}

\author{
1 Jaume I University, Castellón (Spain) \\ 2 Health Research Institut from Aragón, Zaragoza (Spain) \\ 3 University of Zaragoza, Zaragoza (Spain) \\ 4 Human Reproduction Unit, General University Hospital of Castellón, Castellón (Spain)
}

Verónica Martínez-Borba ${ }^{1,2}$, Jorge Osma ${ }^{2,3^{*}}$, Elena Crespo-Delgado ${ }^{1,2}$, Laura Andreu-Pejó ${ }^{1,2}$, and Alba Monferrer-Serrano ${ }^{4}$

\begin{abstract}
Título: Prevención de trastornos y síntomas emocionales en condiciones de salud: estudio piloto aplicando el Protocolo Unificado en una unidad de reproducción humana.

Resumen: Los trastornos emocionales (TE) son frecuentes durante los tratamientos de fertilidad. El Protocolo Unificado (PU) es una intervención transdiagnóstica que ha demostrado su eficacia en la prevención de TE en condiciones médicas. El objetivo de este estudio piloto es: 1) mejorar la disregulación emocional para prevenir síntomas ansiosos y depresivos en mujeres en tratamiento de inseminación artificial (IA); 2) evaluar la aceptabilidad (satisfacción y adherencia). Método: 5 mujeres en tratamiento de IA, sin diagnóstico clínico, respondieron a medidas de estado de ánimo (ansiedad y depresión), afecto, calidad de vida y regulación emocional en el pre- y post-evaluación, y en los seguimientos a los 1, 3 y 6 meses. La adaptación preventiva del PU se basó en la aplicación de 6 sesiones presenciales grupales de 2 horas de duración. La situación generada por la COVID-19 provocó el cambio al formato online para finalizar el programa. Resultados: las mujeres no desarrollaron TE, no se encontraron diferencias pre-post y pre-seguimientos estadísticamente significativas en ansiedad, depresión, calidad de vida y disregulación emocional $(p>.050)$. Se observa una tendencia a la mejoría en la evaluación post-programa. Conclusiones: Parece que programas como el PU, centrado en factores terapéuticos compartidos, ha tenido un efecto emocional preventivo durante IA.

Palabras clave: Protocolo Unificado. Técnicas Reproducción Asistida Formato Grupal. Telesalud. Trastornos Emocionales. Regulación Emocional. Prevención de la Salud.
\end{abstract}

\section{Introduction}

According to the World Health Organization (WHO), infertility is defined as a chronic disease of the reproductive system characterized by the impossibility of achieving pregnancy after 12 months or more of regular sexual relations without using any contraceptive method (Zegers-Hochschild et al., 2010). It is estimated to affect between $1.9 \%$ and $27.1 \%$ of women worldwide (Mascarenhas et al., 2012). The most recent data confirm that demand for Assisted Reproductive Techniques (ART) is globally increasing (Adamson et al., 2018). For example, in Europe more than 600,000 treatment cycles were performed in 2011 and 918,159 treatment cycles in 2016 (Calhaz-Jorge et al., 2020; European IVF-Monitoring Consortium et al., 2016).

Generally, ART could be divided into different stages. They usually begin with simple lifestyle changes or programmed sexual relations, and then progress to complex

* Correspondence address [Dirección para correspondencia]:

Jorge Javier Osma López. Departamento de Psicología y Sociología. Universidad de Zaragoza. C/ Atarazanas 4, 44003, Teruel (Spain).

E-mail: osma@unizar.es

(Article received: 5-1-2021, revised: 17-2-2021, accepted: 1-6-2021)
Abstract: Emotional Disorders (EDs) are common in women who undergo fertility treatments. The Unified Protocol (UP) is a transdiagnostic intervention that has demonstrated efficacy in preventing EDs under different health conditions. The aim of this pilot study is to: 1) improve emotional dysregulation for the prevention of anxiety and depressive symptoms in women undergoing intrauterine inseminations (IUI); 2) assess their acceptability (e.g., satisfaction and adherence rates). Method: Five women undergoing IUI, with no clinical diagnoses, responded to measures of mood (anxiety and depression), affect, quality of life and emotional dysregulation in the pre- and post-assessments, and at the 1-, 3- and 6month follow-ups. The UP was adapted to be applied during six face-toface group sessions lasting $2 \mathrm{~h}$. The COVID-19 pandemic situation implied changing to an online format to end the program. Results: The results showed that women did not develop EDs, and no statistically significant pre-post and pre-follow-up differences were found for anxiety, depression, quality of life and emotional dysregulation (all $p>.050$ ). A tendency towards improvement in the post-assessment evaluation was noted. Satisfaction with the format and UP program was high. Conclusions: It would seem that programs focusing on therapeutic common factors like the UP could have an emotional preventive effect during IUI.

Keywords: Unified Protocol. Assisted Reproduction Techniques. Group format. e-health. Emotional Disorders. Emotion Regulation. Health Prevention. treatments like controlled ovarian hyperstimulation plus intrauterine insemination (IUI), or to increasingly more complex techniques like in vitro fertilisation (IVF; Smith et al., 2011). All these procedures, whether they are effective or not, come with an associated series of risks and possible complications (Ávila \& Moreno-Rosset, 2008) that, together with uncertainty about treatment effectiveness, make the ART process an extremely stressful event (Greil et al., 2011).

Some studies report that between $25 \%$ and $65 \%$ women undergoing fertility treatments present some psychopathology type such as anxiety or depression symptomatology, often with high comorbidity rates between both disorders (i.e., Cox et al., 2006). Recent studies conducted with women undergoing ART report higher depression and anxiety rates than before treatment (Lakatos et al., 2017), which could negatively impact their quality of life, as well as the costeffectiveness of ART and its continuity (i.e., Kiesswetter et al., 2020). These data have worsened with the COVID-19 pandemic because infertility ART stopped from March 15th 2020, and this delay stresses the population undergoing ART (Vaughan et al., 2020).

These data highlight the need to develop and implement programs to prevent the onset of emotional disorders (EDs; anxiety, depression and related disorders; Bullis et al., 2019) 
in women who are involved in ART. Several review studies have analysed those interventions with proven efficacy in reducing stress, anxiety and depressive symptoms in couples undergoing ART (i.e., Ying et al., 2016). Some studies report positive results in the reduction of anxiety and depressive symptoms (Boivin, 2003), while others indicate no beneficial effect of psychological interventions on infertile patients' mental health (Hämmerli et al., 2009). These differences may be the result of the varying psychological interventions applied. Boivin (2003) suggests that group interventions based on education and skills training are more effective. Some studies indicate that symptoms-focused psychosocial interventions based on CBT, mindfulness techniques, stress management and emotion regulation programs could be effective in reducing psychological stress or anxiety and depressive symptoms, and in improving the quality of life of women undergoing ART (Heredia et al., 2020; Li et al., 2019).

Despite the proven efficacy of these symptoms-focused interventions, it remains unclear which of them is more suitable for women undergoing ART. An alternative to the symptoms-focused approach is to implement a transdiagnostic prevention program to improve women's emotion regulation strategies. The Unified Protocol (UP) is a cognitivebehavioural transdiagnostic intervention that focuses on the shared aetiological and maintenance factors underlying EDs, which are related to difficulties in emotion regulation. The UP facilitates the learning of emotional regulation skills to improve tolerance to discomfort deriving from intense emotions, such as sadness, guiltiness or anxiety (Barlow et al., 2017). Previous studies have shown preliminary data for the efficacy of the UP in treating EDs that are comorbid with different health conditions, and are especially prevalent in women (e.g. chronic pain or breast cancer; Payne 2018; Weihs et al., 2019; Osma et al., 2021). Recent studies report promising data about applying the UP in a group format (e.g., Reinholt et al., 2017) and for preventing EDs in different populations (Sauer-Zavala et al., 2020).

Despite such evidence, it would appear that women and couples with fertility problems neither receive the necessary psychological care nor are referred to adequate mental health services (Pasch et al., 2016). Some barriers come down when asking for help, such as the stigma associated with mental health, logistical or financial limitations or health professionals' lack of knowledge and skills (van Dongen et al., 2016; Wischmann, 2008). In this scenario, the use of Information and Communication Technologies (ICT) can provide important advantages that help to overcome the limitations of traditional face-to-face systems (Burger et al., 2020). For instance, it is more anonymous and can reduce the stigma re- lated to mental health consultations, it can be delivered at home and has no travelling barriers, and allows treatments to be continued even when unexpected negative events occur and impede face-to-face interventions, such as the COVID19 pandemic situation (e.g., Vaughan et al., 2020). Furthermore, ICT-based interventions have shown good results for women's acceptability of fertility problems (i.e., van Dongen et al., 2016).

Therefore, the objective of our study focuses on: 1) improving emotional regulation skills to prevent anxiety and depressive symptoms/disorders in women undergoing IUI; 2) assessing the acceptability (e.g., satisfaction and adherence rates) of this program. By taking into account our program's preventive nature, we expected to maintain non-clinical levels of anxiety and depressive symptoms and negative affect after the UP-preventive program (UP-PP), and at the 1-, 3and 6-month follow-ups. We also expected to observe the positive affect, quality of life, and improvements in emotion dysregulation to remain. Finally, we expected to find a high level of satisfaction with the program in terms of the participants' quantitative and qualitative reports and their high adherence rates.

\section{Method}

\section{Participants}

Figure 1 shows the flow diagram of our participants. Twenty-five women treated for fertility problems in a $\mathrm{Hu}-$ man Reproductive Unit (HRU) in the General University public Hospital from Castellón, consented to participate in this study. Of these women, 22 were contacted by a psychologist to arrange the first interview during which inclusion criteria were assessed. As some women did not meet the inclusion criteria (see Figure 1), eight women participated in the study (mean age $=32.88, S D=3.56$, range 28-39). All the women were Spanish, most were in a relationship ( $n=$ $7)$, currently employed $(n=8)$ and had more than 12 years of education $(n=8)$. The time period during which they had attempted pregnancy ranged between 12 and 36 months (mean $=20.50, S D=7.84)$, and the cause of infertility was mainly unknown $(n=4)$, female factor $(n=2)$ and no male partner $(n=2)$. The number of IUI received upon the first assessment was between 1 and 3 cycles (mean $=1.63, S D=0.92)$. Six women received IUI using their partner's sperm, while two did so with anonymous donations. None had previous children. 
Figure 1

Flow diagram of the study participants.

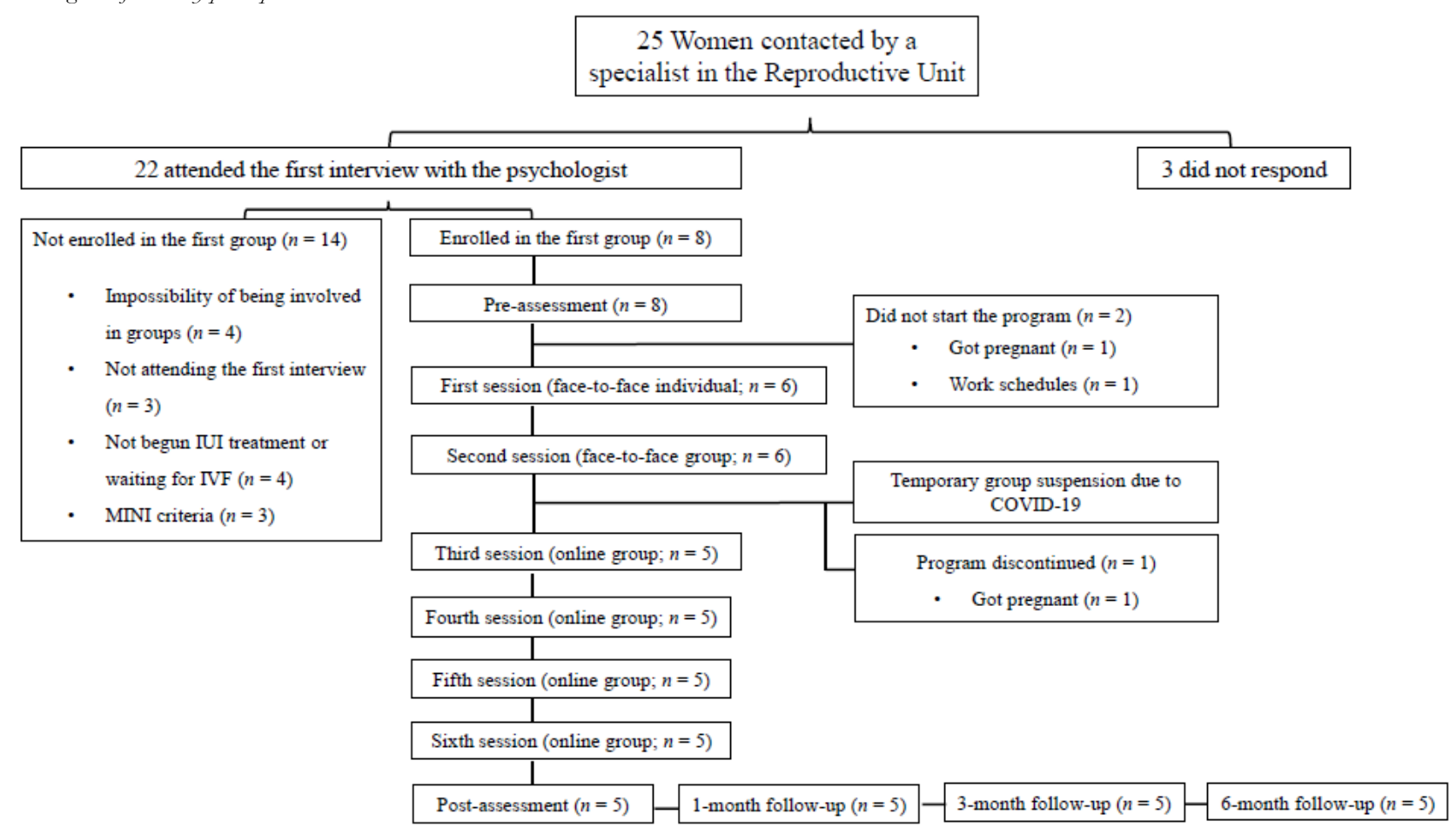

\section{Procedure}

All the procedures were approved by the Ethics Committee of the General University Hospital from Castellón. The study was conducted between September 2019 and November 2020 in the HRU of the aforementioned public hospital.

The women attending the HRU to receive IUI were invited by the doctor responsible for the HRU to voluntarily participate in the UP-PP in face-to-face groups. After providing written informed consent, psychologists conducted the first face-to-face appointment at the hospital where the Mini-International Neuropsychiatric Interview (MINI; Sheehan et al., 1998) was administered to evaluate the exclusion (i.e., diagnostic of mental health disorder or suicide risk at the time of the assessment) and inclusion criteria (i.e., aged over 18 years, undergoing IUI treatment, fluent in Spanish or Catalan, and able to attend all the programmed group sessions). As the women who do not receive fertility treatment usually report fewer distress and depressive symptoms than those receiving these treatments (Lakatos et al., 2017), one inclusion criterion to participate in group sessions was having undergone at least one IUI. The women who had not begun IUI at the time of the first assessment with a psychologist were informed about the possibility of being included in the next groups.
If the women met the inclusion criteria $(n=8)$, before they started UP-PP they completed an online pre-assessment on the Qualtrics platform, a session that lasts approximately 30 minutes. The same instruments were also administered at the post- and three follow-up assessments (1-, 3- and 6month follow-ups).

To ensure proper UP-PP implementation, the psychologist went on a UP training course with clinical supervision by J.O author, who has been certified by the Unified Protocol Institute and has ample experience in applying the UP.

\section{Unified Protocol Prevention Program (UP-PP)}

Table 1 shows the original UP sessions, as well as the adaptations made to this pilot study. The prevention program consisted of weekly sessions during 6 weeks, distributed as one 1-hour individual session and five 2-hour group sessions. The first individual face-to-face session focused on motivation and adjusting expectancies. The second session was also conducted at the hospital with all the women. However, the remaining sessions (program sessions 3 to 6 ) were held online as a result of the COVID-19 pandemic. These sessions were offered over the Zoom platform by maintaining the 2-hour duration of sessions. After each session, the women received an ad hoc manual by email with the information they had learned during every session, including worksheets to register their homework. 
Table 1

Unified Protocol adaptations to the preventive program for the women undergoing IUI.

\begin{tabular}{|c|c|c|}
\hline UP original module & Adapted UP-PP modules & Description of adaptations \\
\hline $\begin{array}{l}\text { Setting goals and } \\
\text { maintaining moti- } \\
\text { vation }\end{array}$ & $\begin{array}{l}\text { Adjusting expectations: emotional changes } \\
\text { and emotional regulation during ART } \\
\text { (INDIVIDUAL AND FACE-TO-FACE) }\end{array}$ & $\begin{array}{l}\text { This module was adapted to talk about emotional changes during fertility } \\
\text { treatments, as well as the importance of emotion regulation before, dur- } \\
\text { ing and after pregnancy. Finally, expectations of IUI, UP-PP and mother- } \\
\text { hood myths were worked out. }\end{array}$ \\
\hline $\begin{array}{l}\text { Understanding } \\
\text { emotions }\end{array}$ & $\begin{array}{l}\text { What do our emotions tell us? Analysis of } \\
\text { emotional experiences } \\
\text { (FACE-TO-FACE GROUP) }\end{array}$ & $\begin{array}{l}\text { This was applied following the UP original structure. Psychoeducation } \\
\text { about emotions and their functions were presented using specific exam- } \\
\text { ples of the fertile treatment process. }\end{array}$ \\
\hline $\begin{array}{l}\text { Mindful Emotion } \\
\text { Awareness }\end{array}$ & $\begin{array}{l}\text { Living in the present to facilitate change } \\
\text { (ONLINE GROUP) }\end{array}$ & $\begin{array}{l}\text { This module was applied following the same contents described in the } \\
\text { original UP. }\end{array}$ \\
\hline $\begin{array}{l}\text { Cognitive flexibili- } \\
\text { ty }\end{array}$ & $\begin{array}{l}\text { My head doesn't help me: worries, doubts } \\
\text { and fears } \\
\text { (ONLINE GROUP) }\end{array}$ & $\begin{array}{l}\text { Here the focus on thoughts was worked on. Women learned how to iden- } \\
\text { tify maladaptive thought patterns and how to be more flexible with spe- } \\
\text { cific fertility examples: "Everybody gets pregnant except me", "I will never get } \\
\text { pregnant" or "I should be happier about my sister's pregnancy". }\end{array}$ \\
\hline $\begin{array}{l}\text { Countering Emo- } \\
\text { tional Behaviours }\end{array}$ & $\begin{array}{l}\text { My Ladder of Opportunity: Behaviour } \\
\text { guided by my goals and values } \\
\text { (ONLINE GROUP) }\end{array}$ & $\begin{array}{l}\text { We adapted this module by explaining Emotion Behaviours and changing } \\
\text { them for Alternative Actions guided by their own goals. In this way, } \\
\text { women thought about their values and planned some behaviours to be } \\
\text { used when emotions were intense, and directed behaviours allowed them } \\
\text { to continue with their personal goals. A problem-solving solution was } \\
\text { added to help women to differentiate whether emotions were justified or } \\
\text { not, and when they needed to be more flexible or evaluate their options } \\
\text { and choose more appropriate ones at that time. }\end{array}$ \\
\hline $\begin{array}{l}\text { Recognizing Ac- } \\
\text { complishments } \\
\text { and looking to the } \\
\text { Future }\end{array}$ & $\begin{array}{l}\text { Emotional release valves: maintaining rein- } \\
\text { forcing and meaningful activities and asser- } \\
\text { tive communication } \\
\text { (ONLINE GROUP) }\end{array}$ & $\begin{array}{l}\text { During this session, we adapted the UP programming future pleasant ac- } \\
\text { tivities to increase their well-being. As difficult conversations may emerge } \\
\text { in the following months, women learned to anticipate them, and also } \\
\text { learned assertive communication techniques to be used with family rela- } \\
\text { tions, friends and coworkers. }\end{array}$ \\
\hline
\end{tabular}

\section{Instruments}

The Mini-International Neuropsychiatric Interview (MINI; Sheehan et al., 1998; Ferrando et al., 1998): it evaluates 16 diagnostic categories according to the Diagnostic and Statistical Manual of Mental Disorders Fourth Edition - Text Revision (DSM-IV-TR; American Psychiatric Association [WHO], 2000) and the ICD-10 Classification of Mental and Behavioural Disorders (World Health Organization [WHO], 1993). The DSM-IV-TR version of MINI was used because it was the only one that psychologists had at the time the assessment was made. Questions about the presence or absence of the symptom were closed and had to be asked by the interviewer. The kappa value for interobserver reliability was around .75 , while test-retest reliability was less than .75 for the DSM-IV-TR version.

Overall Anxiety Severity and Impairment Scale (OASIS; Norman et al., 2006; Osma et al., 2019): it evaluates frequen$\mathrm{cy}$, intensity and interference of anxious symptomatology in the last week. It consists of five items that are rated on a Likert scale ranging from 0 (I didn't feel anxious) to 4 (Constant anxiety). The total score ranges from 0 to 20 . Higher scores indicate greater anxious symptomatology severity. In the Spanish version, the cut-off point set in the clinical sample was 10 points (Osma et al., 2019). OASIS has good internal consistency ( $\alpha=.87$; Osma et al., 2019).

Overall Depression Severity and Impairment Scale (ODSIS; Norman et al., 2006; Osma et al., 2019): it evaluates frequency, intensity and interference of depressive symptoms in the past week. It consists of five items with responses ranging between 0 (I didn't feel depressed) and 4 (Constant depression). Total scores, ranging from 0 to 20 , indicate depressive symptomatology severity. In the Spanish version, the cut-off point in the clinical sample was 10 points (Osma et al., 2019). ODSIS displays excellent psychometric properties $(\alpha=.94$; Osma et al., 2019).

Positive and Negative Affect Schedule (PANAS; Watson et al., 1988; Sandín et al., 1999): it comprises 10 positive affect and 10 negative affect descriptors. These items are rated on a Likert-type scale ranging from 1 (nothing or almost notbing) to 5 (very much). Each scale scores from 10 to 50 . Higher scores indicate a more positive or negative affect. In Spanish women, the normative data for positive and negative affect were mean $=32.52(S D=8.46)$ and mean $=20.61(S D=7.73)$, respectively (López-Gómez et al., 2015). The Spanish version has shown good internal consistency on both the positive $(\alpha=.87)$ and negative affect $(\alpha=.89$; Sandín et al., 1999) scales.

The Fertility Quality of Life tool (FertiQoL; Boivin et al., 2011): it consists of 36 items that assess quality of life related to fertility treatments. Questions are rated on a 5-point Likert scale from 0 (Very poor/very dissatisfied/always/an extreme amount/completely) to 4 (very good/very satisfied/never/not at all). The total score can be calculated by summing all 34 items, two FertiQoL items measure overall physical health and satisfaction with quality of life and are not used in FertiQoL scoring. Total scores ranged between 0 and 136. Higher scores mean better quality of life. For the Spanish women 
undergoing ART, the mean FertiQol score is 68.00 (range 46.00 - 87.00; Heredia et al., 2013). Good psychometric properties are found $(.72 \leq \alpha \leq .92$; Boivin et al., 2011).

Difficulties in Emotion Regulation Scale (DERS; Gratz \& Roemer, 2004; Hervás \& Jódar, 2008): it contains 28 items with 5-point Likert answers from 1 (Never) to 5 (Always) that estimate emotional dysregulation severity. Total scores range from 28 to 140 . Higher scores indicate more difficulties in emotion regulation. In Spanish women, the normative data is mean $=59.10(S D=17.50$; Hervás \& Jódar, 2008). Internal consistency is high in the Spanish version $(\alpha=.74$; Hervás $\&$ Jódar, 2008).

Participants' satisfaction: an ad hoc questionnaire was developed to assess participants' satisfaction with five domains: assessments, online format, emotion regulation, general UPPP satisfaction and UP-PP specific content satisfaction. Each question was rated from 0 (Not satisfied/ not important at all/ any technological issues/ therapeutic alliance maintained/ not belpful) to 10 (Completely satisfied/ very important/ high technological issues/ therapeutic alliance not maintained/ completely helpful).

\section{Statistical analyses}

Firstly, the participants' socio-demographic characteristics were explored. Given the sample distribution, the nonparametrical Mann-Whitney U test was performed to explore the differences in the socio-demographic and psychological variables between completers and non-completers.

Secondly, the evolution of the psychological variables (anxiety and depressive symptoms, affect, quality of life, emotion dysregulation) was analysed according to the prepost assessment and the pre- follow-up assessments (1-, 3-, and 6-month follow-ups). The non-parametric SaphiroWilcoxon test was used.

Finally, satisfaction with the emotion regulation program and the adherence rates were analysed in order to assess users' acceptability. The quantitative analyses included satisfaction with assessments, satisfaction with online group sessions, satisfaction with the UP-PP and adherence rates (attended sessions compared to programmed ones). In addition, qualitative reports of women were presented. All the statistical analyses were performed with SPSS, version 22.0 (IBM Corp, 2013).

\section{Results}

\section{Comparison of Completers and non-completers}

At the beginning, eight women opted to participate in group sessions and then completed the pre-assessment. However, when the first program session began, two women dropped out, which left six women who attended the first individual program session. One additional woman got pregnant between the second and third program sessions and declined the option of continuing in the group.

Comparisons between completers and non-completers were made to determine if the socio-demographic or psychological variables could favour discontinuation with this prevention program. As observed in Table 2, there were no statistical differences at the pre-assessment between the women who completed all the sessions $(n=5)$ and those who discontinued $(n=3)$ for either socio-demographic or psychological status (all $p>.050)$.

Table 2

Socio-demographic and psychological characteristics of completers and non-completers.

\begin{tabular}{|c|c|c|c|c|}
\hline \multirow[t]{2}{*}{ Variable } & $\begin{array}{c}\text { Completers } \\
(n=5)\end{array}$ & $\begin{array}{l}\text { Non-completers } \\
(n=3)\end{array}$ & \multicolumn{2}{|c|}{ Comparison } \\
\hline & Mean (SD); range & Mean (SD); range & $U$ & $p$ \\
\hline Age & $33.80(4.09) ; 28-39$ & $31.33(2.31) ; 30-34$ & 4.00 & .291 \\
\hline Number of received IA & $2(1.00) ; 1-3$ & $1(0.00) ; 1-1$ & 3.00 & .121 \\
\hline \multirow[t]{2}{*}{ Time trying to get pregnant in months } & $19.5(13.30) ; 6-36$ & $20(4.00) ; 16-24$ & 5.50 & .858 \\
\hline & $N(\%)$ & $N(\%)$ & $\chi^{2}$ & $p$ \\
\hline In a relationship & $4(80)$ & $3(100)$ & 0.60 & .439 \\
\hline Currently employed & $5(100)$ & $3(100)$ & - & - \\
\hline More than 12 years of education & $5(100)$ & $3(100)$ & - & - \\
\hline \multicolumn{5}{|l|}{ Infertility cause } \\
\hline Unknown & $2(40)$ & $2(66.67)$ & 0.47 & .494 \\
\hline No male partner & $2(40)$ & 0 & - & - \\
\hline \multicolumn{5}{|l|}{ Type of donation } \\
\hline Partner & $3(60)$ & $3(100)$ & 1.40 & .237 \\
\hline \multirow[t]{2}{*}{ Anonymous } & $2(40)$ & 0 & - & - \\
\hline & Mean (SD); range & Mean (SD); range & $U$ & $p$ \\
\hline Anxiety symptoms & $2.60(2.88) ; 0-7$ & 1.67 (2.08); $0-4$ & 7.00 & .878 \\
\hline Depressive symptoms & $1.80(2.49) ; 0-5$ & $3.00(4.36) ; 0-8$ & 5.50 & .525 \\
\hline Positive affect & $38.40(10.19) ; 27$ - 49 & $35.00(1.00) ; 34-36$ & 6.00 & .655 \\
\hline Negative affect & $21.00(8.86) ; 14-33$ & 16.67 (3.21); 13 - 19 & 6.00 & .653 \\
\hline Quality of life & 91.25 (26.17); 58 - 120 & 101.67 (19.86); $86-124$ & 4.50 & .593 \\
\hline Emotion dysregulation & $52.80(20.92) ; 36-89$ & 51.00 (25.24); $34-80$ & 5.00 & .453 \\
\hline
\end{tabular}




\section{Mood, affect, quality of life and emotion dysregula- tion results}

\section{Mood and affectivity over time}

Table 3 shows the mean scores and standard deviations of the psychological variables assessed before the program (pre), at the end of the program (post) and at the three follow-up points (1-, 3-, and 6-month follow-ups).

Both anxiety and depressive symptoms remained relatively stable under the clinical cut-off set for the Spanish population $(\geq 10)$ during all the assessments. Anxiety and depressive symptoms decreased from the pre- to the postassessment, and then increased at the 1-, 3- and 6-month follow-ups. However, these differences were non-significant (all $p>$.050)

Positive affect remained from the pre- to the postassessment, and slightly decreased at the follow-up assessments (1-, 3-, and 6-month follow-ups). However, as Table 3 shows, all the differences were non-significant (all $p>050$ ). The women included in our study maintained a high positive affect at the end of the program and at the follow-up assessments. The mean score and standard deviation in our sample were higher than the normative data in all five assessments.

The changes in negative affect between the pre- and post-assessment, the pre- and 1-month follow-up and the pre- and 6-month follow-up were non-significant (all $p>$ .050). However, statistically significant differences were found in the scores from the pre- to the 3-month follow-up $(Z=-2.03, p=.042, d=0.75)$, which means that women had lower negative affect at the 3-month follow-up than for the pre-assessment scores. Compared to normative data for Spanish women, our sample obtained higher scores for negative affect at the pre-assessment and the 1-month follow-up. In contrast, this tendency changed at the 3- and 6-month follow-up assessments, when our sample's mean score was lower than the scores reported by Spanish women with no clinical diagnosis of mental disorders.

\section{Quality of life and emotion dysregulation over time}

Quality of life tended to increase from the pre- to the post-assessment, and continued to rise at the 1-month follow-up. The lowest quality of life score was obtained at the 3-month follow-up, when most women had finished their fertility treatment without positive results. Finally, at the 6month follow-up, women reported similar quality of life scores as they did at the pre-assessment. As seen in Table 3, none of these differences was significant (all $p>$.050). Moreover, women gave higher quality of life scores across all five assessments than those reported by other Spanish women undergoing ART.

Emotion dysregulation improved when the program ended (post-assessment) and remained relatively stable at the 1-, 3- and 6-month follow-ups. Once again, these differences were non-significant (all $p>.050$ ). Additionally, emotion dysregulation in our sample was lower at the pre-assessment (mean $=52.80, S D=20.92)$ compared to normative data for Spanish women $($ mean $=59.10, S D=17.50)$, and this difference was also observed at the post-assessment and the 1-, 3and 6-month follow-ups.

Table 3

Mean, standard deviation and changes across UP-PP in psychological variables.

\begin{tabular}{|c|c|c|c|c|c|c|c|c|c|c|c|c|c|c|c|c|c|c|}
\hline & \multirow{2}{*}{\multicolumn{2}{|c|}{ PRE }} & \multirow{2}{*}{\multicolumn{2}{|c|}{ POST }} & \multirow{2}{*}{\multicolumn{2}{|c|}{$1 \mathrm{~m} \mathrm{FU}$}} & \multirow{2}{*}{\multicolumn{2}{|c|}{$3 \mathrm{~m} \mathrm{FU}$}} & \multirow{2}{*}{\multicolumn{2}{|c|}{$6 \mathrm{~m} \mathrm{FU}$}} & \multicolumn{8}{|c|}{ Comparisons } \\
\hline & & & & & & & & & & & PRE-I & $\overline{\text { POST }}$ & PRE-1 & $1 \mathrm{~m} \mathrm{FU}$ & PRE-3 & $3 \mathrm{~m} \mathrm{FU}$ & PRE- & $6 \mathrm{~m} \mathrm{FU}$ \\
\hline & Mean & $S D$ & Mean & $S D$ & Mean & $S D$ & Mean & $S D$ & Mean & $S D$ & $Z$ & $p$ & $Z$ & $p$ & $Z$ & $p$ & $Z$ & $p$ \\
\hline Anxiety symptoms & 2.60 & 2.88 & 2.20 & 1.48 & 4.40 & 3.05 & 4.00 & 3.08 & 5.40 & 2.88 & -0.56 & .577 & -0.95 & .343 & -0.81 & .416 & -1.22 & .223 \\
\hline Depressive symptoms & 1.80 & 2.49 & 0.80 & 1.79 & 1.80 & 4.02 & 2.80 & 4.76 & 2.40 & 2.88 & -1.34 & .180 & 0.00 & .999 & -0.45 & .655 & 0.00 & .999 \\
\hline Positive affect & 38.40 & 10.19 & 38.40 & 12.54 & 36.60 & 7.30 & 36.40 & 9.29 & 37.40 & 11.48 & 0.01 & .999 & -0.37 & .715 & -0.67 & .500 & -0.27 & .786 \\
\hline Negative affect & 21.00 & 8.86 & 18.00 & 8.97 & 22.40 & 8.20 & 15.80 & 4.09 & 19.00 & 5.52 & -1.84 & .066 & -0.41 & 686 & -2.03 & .042 & -0.67 & .500 \\
\hline Quality of life & 91.25 & 26.17 & 95.00 & 11.40 & 100.25 & 13.10 & 85.75 & 17.44 & 91.50 & 18.84 & -0.73 & .465 & -0.37 & .715 & -0.37 & .715 & -0.37 & .713 \\
\hline Emotion dysregulation & 52.80 & 20.92 & 44.00 & 7.11 & 44.60 & 11.44 & 45.00 & 8.80 & 45.20 & 11.58 & -0.67 & .500 & -0.94 & .345 & -0.95 & .343 & -0.94 & .345 \\
\hline
\end{tabular}

\section{UP-PP acceptability}

\section{UP-PP satisfaction}

Firstly, as observed in Table 4, high program satisfaction was indicated. Regarding assessment satisfaction, women reported that the questions were easy to understand and answer. Women generally trusted Qualtrics as a reliable tool to make assessments.

Secondly, women were asked about their satisfaction with the online emotion regulation program. High satisfac- tion was indicated for their participation in groups (i.e., interacting with other women during online sessions). Four participants were satisfied with both the face-to-face and online formats. One participant favoured the face-to-face format over the online sessions. As regards format preferences in a future emotion regulation program, three women preferred the group and face-to-face format, while two women did not mind the format.

Regarding emotion regulation in the fertility process, all the women considered it important to learn emotion regulation skills during IUI. The participants generally considered 
that the UP-PP helped them to manage their emotions and to solve their problems more adaptively. When they contemplated the whole program, they found it useful and would recommend it to women in a similar situation. The participants specifically rated all the skills they had learned in the six program modules. The highest scores were for learning about emotion components, thoughts identification and assertive communication.

Finally, qualitative reports were also analysed. Some women reported that they would like to alternate individual and group sessions with couple sessions. Three women stated that they would prefer it if the program included longer sessions and more sessions during fertility treatment. Other comments included: "I like the structure of sessions; sharing our week's experiences, learning new skills and putting them into practice in real life", "Now I realise the importance of being accompanied by women who are in the same situation", "Thank you so much for thinking of us and seeing that emotion well-being is also important during fertility treatments", "This program helped me to make an appropriate adaptation to not only fertility problems, but also to the pandemic situation".

Table 4

Unified Protocol Preventive Program satisfaction.

\begin{tabular}{|c|c|}
\hline UP-PP evaluation & Mean; $S D$; range \\
\hline \multicolumn{2}{|l|}{ Satisfaction assessment } \\
\hline To what extent did you find the assessment questions through Qualtrics easy to understand? & $8.00 ; 1.73 ; 5-9$ \\
\hline To what extent did you find the assessment questions through Qualtrics easy to answer? & $8.40 ; 1.95 ; 5-10$ \\
\hline To what extent did you feel comfortable answering evaluation questions through Qualtrics? & 10 \\
\hline To what extent did you trust the adequate HANDLING of the information collected through Qualtrics? & $9.8 ; 0.44 ; 9-10$ \\
\hline To what extent did you have technical difficulties using Qualtrics? & $0.20 ; 0.45 ; 0-1$ \\
\hline To what extent were you able to contact the psychologists responsible for the program if you needed to? & 10 \\
\hline \multicolumn{2}{|l|}{ Satisfaction online form } \\
\hline To what extent did you feel you have been listened to during the online group sessions? & 10 \\
\hline To what extent did you feel you have been able to participate actively in the online group? & $9.40 ; 0.89 ; 8-10$ \\
\hline To what extent were you able to interact with the other women in the group during the online sessions? & $9.0 ; 1.00 ; 8-10$ \\
\hline To what extent were you able to maintain concentration and attention during online sessions? & $9.0 ; 1.00 ; 8-10$ \\
\hline To what extent did you feel that the online system had affected the therapeutic alliance? & $2.8 ; 2.68 ; 0-7$ \\
\hline \multicolumn{2}{|l|}{ Emotion regulation during the fertility process } \\
\hline To what extent did you feel that it is important to learn emotional regulation strategies during ART? & $9.8 ; 0.45 ; 9-10$ \\
\hline To what extent did you feel that the UP-PP helped you to regulate your emotions in an adaptive manner? & $9.0 ; 1.73 ; 6-10$ \\
\hline To what extend did the contents you learned helped you to solve your problems effectively? & $9.8 ; 0.45 ; 9-10$ \\
\hline \multicolumn{2}{|l|}{ General UP-PP satisfaction } \\
\hline In general, how would you rate the quality of the program you received? & $9.8 ; 0.45 ; 9-10$ \\
\hline In general, how would you rate the usefulness of the program you received? & 10 \\
\hline To what extent did this program cause you any discomfort? & $0.60 ; 0.89 ; 0-2$ \\
\hline Overall, how satisfied are you with the program? & 10 \\
\hline Would you recommend this program to a family relative or friend in your situation? & 10 \\
\hline \multicolumn{2}{|l|}{ UP-PP specific content satisfaction } \\
\hline \multicolumn{2}{|l|}{ To what extent did each skill learned in the UP-PP help you to adequately regulate your emotions? } \\
\hline Learning about emotion components, thoughts, physical sensations and behaviours & $9.4 ; 0.89 ; 8-10$ \\
\hline Thoughts identification & $9.4 ; 0.55 ; 9-10$ \\
\hline Assertive communication skills & $9.4 ; 1.34 ; 7-10$ \\
\hline Recognising emotional experiences & $9.2 ; 0.83 ; 8-10$ \\
\hline Mindfulness techniques & $9.2 ; 1.30 ; 7-10$ \\
\hline Cognitive flexibility & $9.2 ; 0.84 ; 8-10$ \\
\hline Emotional driven behaviours identification & $9.2 ; 0.84 ; 8-10$ \\
\hline Problem-solving skills & $9.2 ; 0.84 ; 8-10$ \\
\hline Opposed behaviours technique & $8.8 ; 1.30 ; 7-10$ \\
\hline
\end{tabular}

$0=$ Not satisfied/ not important at all/ any technological issues/ therapeutic alliance maintained/ not helpful

$10=$ Completely satisfied/ very important/ high technological issues/ therapeutic alliance not maintained/ completely helpful

\section{Adherence rates}

Six women started the emotion regulation program, and only one woman dropped out after the two initial sessions when she got pregnant. This means that $80 \%$ of them completed all six program sessions and the three follow-up assessments.

\section{Discussion}

Due to the importance of emotion regulation during fertility treatments (Galhardo et al., 2013), and the fact that standardised protocols for EDs prevention are lacking, the objectives of the present study were to: 1) improve emotional dysregulation for the prevention of anxiety and depressive symptoms/disorders in women undergoing IUI; 2) assess their acceptability (e.g., satisfaction with and adherence rates to 
the program). Our results confirmed our hypothesis because no participant presented clinical symptoms or EDs at the end of the program or after the 6-month follow-up assessment, and negative affect continued at non-clinical levels. In addition, the scores for positive affect and quality of life remained, and emotion dysregulation decreased. Finally, the adherence rates and satisfaction reported by the women who participated in this study were both high. However, given the novelty of this program and its pilot nature, we broadly discuss our results below.

Firstly, as regards EDs prevention, the women at the pre-assessment presented no clinical anxiety and depression symptoms, and scores were similar at the post- and followup assessments. These preliminary results are encouraging because the participants had high distress levels (during the program and follow-ups) not only because of the IUI treatments itself (Cox et al., 2006), but because they did not achieve their goals while other women did, and also because the pandemic stopped treatments, which increased their uncertainty, along with other consequences of the pandemic (e.g. restricted mobility, health concerns, economic difficulties, etc.). Despite all these factors, the women participating in this brief prevention program were able to tolerate their intense emotional responses and adhered to their goals. Thus, we suggest that the brief UP-PP could be a useful preventive program to reduce the probability of EDs or clinical symptoms onset during IUI treatments.

Overall, affect seems an important factor to be considered in infertile populations given its relation to quality of life (Kiesswetter et al., 2020). Our results indicated that the brief UP-PP could help to maintain positive affect across IUI sessions. In addition, our preventive program brought about a significant decrease in negative affect, especially from the pre-assessment to the 3-month follow-up. While previous studies have found that negative affect increased in women with repeated ART failure (Coughlan et al., 2014), our result seemed to indicate that if women learned emotion regulation skills, they would be able to maintain lower negative affect scores even though they did not get pregnant, suffered miscarriages or fertility treatments were discontinued due to external events (i.e., COVID-19 pandemic). As previously suggested, programs based on improving cognitive coping skills could improve depressive symptoms as well as positive and negative affect (Kraaij et al., 2009). In light of our results, the brief UP-PP could serve this purpose.

The literature has recently focused on not only impaired psychological functioning, but also on maintaining and promoting a positive perception of quality of life as an intervention target (Gallagher et al., 2013). For this reason, our objective was to maintain the quality of life of the women undergoing IUI. Our results indicated an improved quality of live tendency from the pre- to the post-assessment and the 1-month follow-up, but a decreased tendency was observed at the 3-month follow-up. At the end of the assessments (at the 6-month follow-up), women reported comparable quality of life scores to those recorded at the pre-assessment. This is congruent with previous studies, which have proposed the UP as a useful intervention for this purpose (Sakiris \& Berle, 2019). As we found in our study at the 3-month follow-up, quality of life maintenance is especially relevant at the end of IUI treatments. At this stage, women without a satisfactory result (i.e., not getting pregnant, miscarrying) should consider looking for other treatment options (i.e., IVF in public or private centres), which could lead to lower quality of life scores. For this reason, future studies should consider that if the prevention program finishes before IUI treatments end, a follow-up session must be held at around this time because it is when women need special support.

The latest variable included in our study was emotion dysregulation. Previous studies have found that emotional regulation processes are important for the psychological functioning of people with infertility (Galhardo et al., 2013). For this reason, we suggest that, throughout our brief adapted UP-PP, the women undergoing IUI can learn adaptive emotional strategies to better cope with stressful situations and the intense emotions related to them. Our results revealed an improvement in emotion dysregulation from the pre- to the post-assessment, and this improvement continued at the 1-, 3- and 6-month follow-ups. Despite these differences being non-significant, an improvement tendency was observed.

Regarding our second objective, and in line with previous studies (e.g., Martínez-Borba et al., 2019), high satisfaction with assessments made over Internet was herein noted. However, we should consider that the women in our study had a high level of education, which might imply that our sample found the questions easier to understand and respond than women with a lower level of education.

In addition, satisfaction with the online delivery format was also assessed. Despite the change in format delivery, the interaction between the participants, and also between the participants and the therapist, was not altered. Therefore, women reported having no trouble with maintaining the therapeutic alliance. As a result, only one woman preferred face-to-face sessions over online contact. Despite the advantages reported by online interventions, it would seem that some women still prefer face-to-face programs (Osma et al., 2020). This can be explained by it not being common for the Spanish public health system to offer such services with online tools. Although women would consider a computerbased therapy as their top choice (Hantsoo et al., 2017), public services still rely on face-to-face interventions. So future efforts should promote the use of online interventions in public health settings.

Regarding the relevance of emotion regulation during IUI and satisfaction with the UP-PP, all the women agreed that emotion regulation during fertility programs is particularly important and rated the UP-PP as a high-quality program. They also considered it helpful to manage their emotions and to solve their problems. These results are congruent with previous studies, which have found high satisfaction levels with a brief preventive UP application in the online 
format (Sauer-Zavala et al., 2020), and suggest that an adapted UP-PP is well accepted by women undergoing IUI. It is really important because preventive programs need to be accepted and adjusted to the women's needs (Vázquez et al., 2014).

The women's qualitative reports were also included in this study. As previously mentioned, the women who participated in this group had experienced stressful situations associated with the pandemic situation (i.e., involuntarily discontinuing fertility treatments, economic difficulties, mobility restrictions, etc.). In relation to these additional difficulties, the women reported "we appreciate that you have continued the UP-PP during COVID-19 because we need it more than ever, especially because fertility treatments are discontinued'. The women also valued being in contact with other women undergoing IUI "we need to talk about this with other women". These qualitative opinions indicated that the group format is extremely useful for facilitating peer support, symptoms validation and vicarious learning (Yalom \& Leszcz, 2005). As previous research has found, peer support is fundamental in infertile populations and can be delivered via online devices (Grunberg et al., 2018). The women's quantitative and qualitative reports indicated their good acceptability of the online group sessions. Thus including the Internet group format in future prevention programs seems feasible and needs to be developed particularly in smaller settings, such as rural practices or small towns (Bennett \& Glasgow, 2009) where healthcare access equity may not be guaranteed.

Previous UP online studies have found difficulties in maintaining the sample throughout sessions (45\% of the participants completed the program; Sauer-Zavala et al., 2020). Our adherence rates were high because $80 \%$ of the women who started the program attended the whole program and all the follow-up sessions. While some studies indicate that depressive symptoms can result in discontinuing ART (Pedro et al., 2017), adjusting expectancies about IUI outcomes is important to appropriately adapt to negative results and to lower dropout rates. According to our experience, women do not abandon fertility treatments because they change their objective (i.e., no longer wanting to get pregnant), but because of emotionally driven behaviours (i.e., "I am sad and anxious, and I decided to stop fertility treatment to avoid experiencing these emotions"). Hence the brief adapted UPPP can help women to learn about emotionally driven behaviours and might prevent them from dropping out.

All these results highlight the preventive utility of the brief UP-PP for those women undergoing IUI. However, findings from this pilot study should be interpreted according to its limitations. This is a pilot study with a small sample size and no comparison group, which limits the generalisation of its results, and hypothesis testing should be considered preliminary and interpreted cautiously. Future efforts should be made to recruit a bigger sample size or to even conduct a randomised controlled study with a control group. While acknowledging the limitations of pilot studies, they are considered an essential step in a research project because they allow issues and deficiencies to be identified in the research protocol and instruments before conducting a larger study (Lancaster et al., 2004). In our case, it allowed us to perform a preliminary study on the "utility and acceptability" of implementing a preventive program in an HRU with an online format, and to develop a manualized protocol including the UP contents adapted to specific infertile women to be used in the next groups. It also allowed us to make changes according to the pilot study results. For instance, in line with the women's reports and their experience in group sessions, we decided to add another session, which means that the future brief UP-PP will comprise seven sessions. In addition, and in accordance with women's reports, future efforts should be made to include couples in preventive interventions.

Secondly, those women undergoing IVF were excluded, as this treatment was delivered in another public hospital and in a different city. Future studies should be conducted to prove whether the results herein obtained are replicable in other health services for women with infertility, such as IVF treatments. In addition, our participants were recruited in a public health unit so, once again, our results are not necessarily generalizable to all women and all services. Thirdly, our sample was entirely Spanish. New studies must be conducted with a culturally-sensitive approach to care, and must include migrant communities to study the intercultural efficacy and viability of this prevention program or if adaptations made with these relevant aspects must be contemplated. Finally, only completers provided satisfaction feedback on the UP program and format delivery, which could be interpreted as positive qualifications being overrepresented.

\section{Conclusion}

This is the first study to offer preliminary data about the mid-term (6-month follow-up) utility and acceptability of a brief adapted UP-PP application with an online group format in a public HRU. As recently suggested, moving face-toface UP programs to the online context is urged (SauerZavala et al., 2020) to reduce healthcare access disparities. The pandemic situation brought about the chance to implement this brief UP-PP online, which is especially relevant in our context because the women undergoing IUI usually work and might find it complicated to spend free time attending face-to-face sessions. In addition, the women who attended the HRU came from different places. The online program avoids travelling to group sessions. Overall, our preliminary outcomes suggest that a brief emotional regulation-based preventive program delivered with an online group format is feasible and useful for preventing clinical symptoms/EDs, and also for maintaining affect, quality of life and emotion regulation in women during IUI. The results of this pilot study also indicated that the women who attend an HRU should benefit from a multidisciplinary approach because it would take into account both their physical and emotional necessities. Healthcare providers and 
managers must consider these encouraging preliminary results to guarantee comprehensive health interventions for all the women attending this specific HRU.

Conflict of interest: The authors declare that they have no conflict of interest.

Funding: This research was funded by the Universitat Jaume I (PREDOC/2018/43); the Gobierno de Aragon (Departamento de

\section{References}

Adamson, G. D., de Mouzon, J., Chambers, G. M., Zegers-Hochschild, F., Mansour, R., Ishihara, O., Banker, M., \& Dyer, S. (2018). International Committee for Monitoring Assisted Reproductive Technology: world report on assisted reproductive technology, 2011. Fertility and Sterility, 110(6), 1067-1080. https://doi.org/10.1016/j.fertnstert.2018.06.039

American Psychiatric Association. (2000). Diagnostic and statistical manual for mental disorders: DSM-IV-TR. American Psychiatric Association.

Ávila, A., \& Moreno-Rosset, C. (2008). La intervención psicológica en infertilidad: Orientaciones para un protocolo de actuación clínica Psychological intervention in infertility: Guidelines for a clinical intervention protocol]. Papeles Del Psicologo, 29(2), 186-196.

Barlow, D. H., Farchione, T. J., Bullis, J. R., Gallagher, M. W., Murray-Latin, H., Sauer-Zavala, S., Bentley, K. H., Thompson-Hollands, J., Conklin, L. R., Boswell, J. F., Ametaj, A., Carl, J. R., Boettcher, H. T., \& Cassiello-Robbins, C. (2017). The unified protocol for transdiagnostic treatment of Emotional Disorders compared with diagnosis-specific protocols for anxiety disorders: A randomized clinical trial. $J A M A$ Psychiatry, 74(9), 875-884. https://doi.org/10.1001/jamapsychiatry.2017.2164

Bennett, G. G., \& Glasgow, R. E. (2009). The Delivery of Public Health Interventions via the Internet: Actualizing Their Potential. Annual Review of Public Health, 30, 273-292. https://doi.org/10.1146/annurev.publhealth.031308.100235

Boivin, J. (2003). A review of psychosocial interventions in infertility. Social Science \& Medicine, 57(12), 2325-2341. https://doi.org/10.1016/S02779536(03)00138-2

Boivin, Jacky, Takefman, J., \& Braverman, A. (2011). The Fertility Quality of Life (FertiQoL) tool: development and general psychometric properties. Fertility and Sterility, 96(2), 409-415.e3. https://doi.org/10.1016/j.fertnstert.2011.02.046

Bullis, J. R., Boettcher, H., Sauer-Zavala, S., Farchione, T. J., \& Barlow, D. H. (2019). What is an emotional disorder? A transdiagnostic mechanistic definition with implications for assessment, treatment, and prevention. Clinical Psychology: Science and Practice, 26(2). https://doi.org/10.1111/cpsp.12278

Burger, F., Neerincx, M. A., \& Brinkman, W.-P. (2020). Technological State of the Art of Electronic Mental Health Interventions for Major Depressive Disorder: Systematic Literature Review. Journal of Medical Internet Research, 22(1), e12599. https://doi.org/10.2196/12599

Calhaz-Jorge, C., De Geyter, C. h, Kupka, M. S., Wyns, C., Mocanu, E., Motrenko, T., Scaravelli, G., Smeenk, J., Vidakovic, S., \& Goossens, V. (2020). Survey on ART and IUI: legislation, regulation, funding and registries in European countries. Human Reproduction Open, 2020(1). https://doi.org/10.1093/hropen/hoz044

Coughlan, C., Walters, S., Ledger, W., \& Li, T. C. (2014). A comparison of psychological stress among women with and without reproductive failure. International Journal of Gynecology and Obstetrics, 124(2), 143-147. https://doi.org/10.1016/j.ijgo.2013.08.006

Cox, S. J., Glazebrook, C., Sheard, C., Ndukwe, G., \& Oates, M. (2006). Maternal self-esteem after successful treatment for infertility. Fertility and Sterility, 85(1), 84-89. https://doi.org/10.1016/j.fertnstert.2005.07.1287

European IVF-Monitoring Consortium, European Society of Human Reproduction and Embryology, Kupka, M., D'Hooghe, T., Ferraretti, A., de Mouzon, J., Erb, K., Castilla, J., Calhaz-Jorge, C., De Geyter, C.,
Innovación, Investigación y Universidad) and Feder 2014-2020 "Construyendo Europa desde Aragón" (research group grant S31_20D).

Acknowledgements: We would like to thank all the women who voluntarily participated in this study for their generosity, and all the health professionals working in the Human Reproduction Unit of the General University Hospital of Castellón for their research commitment.
\& Goossens, V. (2016). Assisted reproductive technology in Europe, 2011: results generated from European registers by ESHRE. Human Reproduction, 31(2), 233-248. https://doi.org/10.1093/humrep/dev319

Ferrando, L., Bobes, J., Gibert, M., Soto, M., \& Soto, O. (1998). M.I.N.I Mini International Neuropsychiatric Interview. Versión en español 5.0.0. DSMIV. Instituto IAP.

Galhardo, A., Cunha, M., Pinto-Gouveia, J., \& Matos, M. (2013). The Mediator Role of Emotion Regulation Processes on Infertility-Related Stress. Journal of Clinical Psychology in Medical Settings, 20(4), 497-507. https://doi.org/10.1007/s10880-013-9370-3

Gallagher, M., Sauer-Zavala, S., Boswell, J., Carls, J., Bullis, J., Farchione, T., \& Barlow, D. (2013). The impact of the Unified Protocol for Emotional Disorders on Quality of Life. Inernational Journal of Cognitive Therapy, 6(1), 57-72. https://doi.org/10.1521/ijct.2013.6.1.57

Gratz, K. L., \& Roemer, L. (2004). Multidimensional Assessment of Emotion Regulation and Dysregulation: Development, Factor Structure, and Initial Validation of the Difficulties in Emotion Regulation Scale. Journal of Psychopathology and Behavioral Assessment, 26(1), 41-54. https://doi.org/10.1023/B:JOBA.0000007455.08539.94

Greil, A., McQuillan, J., Lowry, M., \& Shreffler, K. (2011). Infertility Treatment and Fertility-Specific Distress: A Longitudinal Analysis of a Population-Based Sample of U.S. Women. Social Science \& Medicine, 73(1), 87. https://doi.org/10.1016/J.SOCSCIMED.2011.04.023

Grunberg, P. H., Dennis, C.-L., Da Costa, D., \& Zelkowitz, P. (2018) Infertility patients' need and preferences for online peer support. Reproductive Biomedicine \& Society Online, 6, 80-89. https://doi.org/10.1016/j.rbms.2018.10.016

Hämmerli, K., Znoj, H., \& Barth, J. (2009). The efficacy of psychological interventions for infertile patients: a meta-analysis examining mental health and pregnancy rate. Human Reproduction Update, 15(3), 279-295. https://doi.org/10.1093/humupd/dmp002

Hantsoo, L., Podcasy, J., Sammel, M., Epperson, C. N., \& Kim, D. R. (2017). Pregnancy and the Acceptability of Computer-Based Versus Traditional Mental Health Treatments. Journal of Women's Health (2002), 26(10), 1106-1113. https://doi.org/10.1089/jwh.2016.6255

Heredia, A., Padilla, F., Castilla, J. A., \& Garcia-Retamero, R. (2020). Effectiveness of a psychological intervention focused on stress management for women prior to IVF. Journal of Reproductive and Infant Psychology, 38(2), 113-126. https://doi.org/10.1080/02646838.2019.1601170

Heredia, M., Tenías, J. M., Rocio, R., Amparo, F., Calleja, M. A., \& Valenzuela, J. C. (2013). Quality of life and predictive factors in patients undergoing assisted reproduction techniques. European Journal of Obstetrics and Gynecology and Reproductive Biology, 167(2), 176-180. https://doi.org/10.1016/j.ejogrb.2012.12.011

Hervás, G., \& Jódar, R. (2008). The Spanish version of the Difficulties in Emotion Regulation Scale. Clinica y Salud, 19(2), 139-156.

IBM Corp. (2013). IBM SPSS Statistics for Windows, Version 22.0. IBM Corp.

Kiesswetter, M., Marsoner, H., Luehwink, A., Fistarol, M., Mahlknecht, A., \& Duschek, S. (2020). Impairments in life satisfaction in infertility: Associations with perceived stress, affectivity, partnership quality, social support and the desire to have a child. Behavioral Medicine, 46(2), 130 141. https://doi.org/10.1080/08964289.2018.1564897

Kraaij, V., Garnefski, N., \& Schroevers, M. J. (2009). Coping, goal adjustment, and positive and negative affect in definitive infertility. 
Journal of Health Psychology, 14(1), 18-26. https://doi.org/10.1177/1359105308097939

Lakatos, E., Szigeti, J., Ujma, P., Sexty, R., \& Balog, P. (2017). Anxiety and depression among infertile women: a cross-sectional survey from Hungary. BMC Women's Health, 17(1), 48. https://doi.org/10.1186/s12905-017-0410-2

Lancaster, G. A., Dodd, S., \& Williamson, P. R. (2004). Design and analysis of pilot studies: Recommendations for good practice. Journal of Evaluation in Clinical Practice, 10(2), 307-312. https://doi.org/10.1111/j..2002.384.doc.x

Li, J., Luo, H., \& Long, L. (2019). Mindfulness and fertility quality of life in Chinese women with infertility: assessing the mediating roles of acceptance, autonomy and self-regulation. Journal of Reproductive and Infant $\quad$ Psychology, $\quad 37(5), \quad$ 455-467. https://doi.org/10.1080/02646838.2019.1577958

López-Gómez, I., Hervás, G., \& Vázquez, C. (2015). Adaptación de las "escalas de afecto positivo y negativo" (PANAS) en una muestra general Española [Spanish adaptation of the "Positive and Negative Affect Scales" (PANAS) in a general population]. Behavioral Psychology/ Psicologia Conductual, 23(3), 529-548.

Martínez-Borba, V., Suso-ribera, C., \& Osma, J. (2019). Usability, Acceptability, and Feasibility of Two Technology-Based Devices for Mental Health Screening in Perinatal Care: A Comparison of Web Versus App. In P. Cipresso, S. Serino, \& D. Villani (Eds.), Pervasive Computing Paradigms for Mental Health (pp. 176-189). Springer. https://doi.org/10.1007/978-3-319-74935-8

Mascarenhas, M. N., Flaxman, S. R., Boerma, T., Vanderpoel, S., \& Stevens, G. A. (2012). National, Regional, and Global Trends in Infertility Prevalence Since 1990: A Systematic Analysis of 277 Health Surveys. PLoS Medicine, $\quad 9(12), \quad$ e1001356. https://doi.org/10.1371/journal.pmed.1001356

Norman, S. B., Hami Cissell, S., Means-Christensen, A. J., \& Stein, M. B. (2006). Development and validation of an Overall Anxiety Severity And Impairment Scale (OASIS). Depression and Anxiety, 23(4), 245-249. https://doi.org/10.1002/da.20182

Osma, J., Martínez-García, L., Quilez-Orden, A., \& Peris-Baquero, Ó. (2021). Unified Protocol for the Transdiagnostic Treatment of Emotional Disorders in Medical Conditions: A Systematic Review. International Journal of Environmental Research and Public Health, 18(10), 5077. https://doi.org/10.3390/ijerph18105077

Osma, J., Quilez-Orden, A., Suso-Ribera, C., Peris-Baquero, O., Norman, S., Bentley, K., \& Sauer-Zavala, S. (2019). Psychometric properties and validation of the Spanish versions of the overall anxiety and depression severity and impairment scales. Journal of Affective Disorders, 252, 9-18. https://doi.org/10.1016/j.jad.2019.03.063

Osma, J., Suso-Ribera, C., Martínez-Borba, V., \& Barrera, A. Z. (2020). Content and format preferences of a depression prevention program: $A$ study in perinatal women. Anales de Psicologia, 36(1), 56-63. https://doi.org/10.6018/analesps.356051

Pasch, L. A., Holley, S. R., Bleil, M. E., Shehab, D., Katz, P. P., \& Adler, N. E. (2016). Addressing the needs of fertility treatment patients and their partners: are they informed of and do they receive mental health services? Fertility and Sterility, 106(1), 209-215.e2. https://doi.org/10.1016/j.fertnstert.2016.03.006

Payne, L. (2018). Applications of the unified protocol for transdiagnostic treatment of emotional disorders. In D. Barlow \& T. Farchione (Eds.), The unified protocol for cbronic pain (pp. 215-231). Oxford University Press.

Pedro, J., Sobral, M. P., Mesquita-Guimarães, J., Leal, C., Costa, M. E., \& Martins, M. V. (2017). Couples' discontinuation of fertility treatments: a longitudinal study on demographic, biomedical, and psychosocial risk factors. Journal of Assisted Reproduction and Genetics, 34(2), 217-224. https://doi.org/10.1007/s10815-016-0844-8

Reinholt, N., Aharoni, R., Winding, C., Rosenberg, N., Rosenbaum, B., \& Arnfred, S. (2017). Transdiagnostic group CBT for anxiety disorders: the unified protocol in mental health services. Cognitive Behaviour Therapy, 46(1), 29-43. https://doi.org/10.1080/16506073.2016.1227360

Sakiris, N., \& Berle, D. (2019). A systematic review and meta-analysis of the Unified Protocol as a transdiagnostic emotion regulation based intervention. Clinical Psychology Review, 72, 101751. https://doi.org/10.1016/j.cpr.2019.101751

Sandín, B., Chorot, P., Lostao, L., Joiner, T. E., Santed, M. A., \& Valiente, R. M. (1999). Escalas PANAS de afecto positivo y negativo: Validacion factorial y convergencia transcultural [Positive and negative affect scales: factorial validation and cross-cultural convergence]. Psicothema, 11(1), 37-51. https://doi.org/ISSN 0214-9915

Sauer-Zavala, S., Tirpak, J. W., Eustis, E. H., Woods, B. K., \& Russell, K. (2020). Unified Protocol for the Transdiagnostic Prevention of Emotional Disorders: Evaluation of a Brief, Online Course for College Freshmen. Behavior Therapy, in press. https://doi.org/10.1016/j.beth.2020.01.010

Sheehan, D., Lecrubier, Y., Sheehan, K., Amorim, P., Janavs, J., Weiller, E., Hergueta, T., Baker, R., \& Dunbar, G. (1998). The Mini-International Neuropsychiatric Interview (M.I.N.I.): The Development and Validation of a Structured Diagnostic Psychiatric Interview for DSMIV and ICD-10. The Journal of Clinical Psychiatry, 59(20), 22-33.

Smith, J. F., Eisenberg, M. L., Millstein, S. G., Nachtigall, R. D., Sadetsky, N., Cedars, M. I., \& Katz, P. P. (2011). Fertility treatments and outcomes among couples seeking fertility care: data from a prospective fertility cohort in the United States. Fertility and Sterility, 95(1), 79-84. https://doi.org/10.1016/i.fertnstert.2010.06.043

van Dongen, A., Nelen, W., IntHout, J., Kremer, J., \& Verhaak, C. (2016). e-Therapy to reduce emotional distress in women undergoing assisted reproductive technology (ART): a feasibility randomized controlled trial. Human Reproduction, 31(5), 1046-1057. https://doi.org/10.1093/humrep/dew040

Vaughan, D. A., Shah, J. S., Penzias, A. S., Domar, A. D., \& Toth, T. L. (2020). Infertility remains a top stressor despite the COVID-19 pandemic. Reproductive BioMedicine Online, 41(3), 425-427. https://doi.org/10.1016/j.rbmo.2020.05.015

Vázquez, F. L., Blanco, V., Torres, Á., Otero, P., \& Hermida, E. (2014). La eficacia de la prevención indicada de la depresión: Una revisión [The efficacy of indicated prevention of depression: A review]. Anales de Psicologia, 30(1), 9-24. https://doi.org/10.6018/analesps.30.1.138931

Watson, D., Clark, L., \& Tellegen, A. (1988). Development and validation of brief measures of positive and negative affect: the PANAS scales. Journal of Personality and Social Psychology, 54(6), 1063-1070

Weihs, K. L., Mairead, I., Mcconnell, H., Wiley, J. F., Crespi, C. M., SauerZavala, S., \& Stanton, A. L. (2019). A preventive intervention to modify depression risk targets after breast cancer diagnosis: Design and singlearm pilot study. Psycho-Oncology, 28, 880-887. https://doi.org/10.1002/pon.5037

World Health Organization (WHO). (1993). The ICD-10 classification of mental and behavioural disorders. World Health Organization

Wischmann, T. (2008). Implications of psychosocial support in infertility - a critical appraisal. Journal of Psychosomatic Obstetrics \& Gynecology, 29(2), 8390. https://doi.org/10.1080/01674820701817870

Yalom, I., \& Leszcz, M. (2005). The theory and practice of group therapy 5 th ed. IUP.

Ying, L., Wu, L. H., \& Loke, A. Y. (2016). The effects of psychosocial interventions on the mental health, pregnancy rates, and marital function of infertile couples undergoing in vitro fertilization: a systematic review. Journal of Assisted Reproduction and Genetics, 33(6), 689701. https://doi.org/10.1007/s10815-016-0690-8

Zegers-Hochschild, F., Adamson, G., de Mouzon, J., Ishihara, O., Mansour, R., Nygren, K., Sullivan, E., Van der Poel, S., \& WHO. (2010). Glosario de terminología en Técnicas de Reproducción Asistida (TRA) [Glossary of terminology in Assisted Reproductive Technologies (ART)]. In Red Latioamericana de Reproducción Asistida. 